\title{
IMPLEMENTASI WEB-SCADA UNTUK ME-MONITOR BESARAN LISTRIK DI GEDUNG ELEKTRO KAMPUS 1 POLITEKNIK NEGERI UJUNG PANDANG
}

\author{
Nurlaila Azizah ${ }^{1)}$, Dian Pratiwi ${ }^{2)}$ \\ 1)2) Jurusan Teknik Elektro, Politeknik Negeri Ujung Pandang \\ email: Azizahnurlaila21@gmail.com ${ }^{1)}$,dianpratiwi628@gmail.com ${ }^{2}$
}

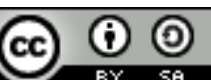

\begin{abstract}
Abstrak
Tujuan tugas akhir ini adalah memodifikasi suatu peralatan yang sudah terpasang dengan menambahkan penyimpanan data hasil pengukuran besaran listrik secara real time yang dapat diakses melalui jaringan web untuk menggantikan system pengukuran secara manual dan konvensional agar dapat mempermudah operator dalam membuat keputusan-keputusan terkait pada gedung Teknik Elektro Politeknik Negeri Ujung Pandang. System pendukung yang dibuat memanfaatkan Power Logic Schneider PM-5350 yang terintegrasi dengan komunikasi data melalui Ethernet yang selanjutnya ditampilkan dalam bentuk visualisasi yang mudah dipahami oleh pengguna.Metode yang digunakan pada tugas akhir ini, menggunakan metode rancang bangun yang terdiri dari beberapa tahap, yaitu: (1)identifikasi kebutuhan, (2)Konsep Rancangan, (3)Pembuatan, dan (4)Pengujian. Monitoring besaran listrik di Gedung Elektro Kampus 1 Politeknik Negeri Ujung Pandang terdiri dari: (1)Power Meter berfungsi untuk membaca data besaran listrik yang terhubung dengan PLC, yang mana (2) PLC bertugas membaca hasil pembacaan besaran listrik dari PM-5350, dengan menggunakan komunikasi data melalui Ethernet. PLC yang saling terhubungan dengan Personal Computer, (3) aplikasi integraXor bertugas membuat visualisasi SCADA yang juga saling terintegrasi dengan (4) aplikasi So Machine sebagai virtual komunikasi PLC dengan Personal Computer. Pada visualisasi di HMI- GXU3512 ditampilkan hasil pembacaan besaran listrik yang telah dibuat, di aplikasi Integraxor. Sedangkan, untuk mengakses SCADA yang telah dibuat via web, yaitu dengan memanfaatkan fitur bawaan dari aplikasi Integraxor. Hasil penelitian menunjukkan bahwa hasil monitoring besaran listrik melalui web tidak terlihat jauh berbeda dengan hasil monitoring pada power meter. Hasil visualisasi SCADA akan menampilkan data besaran listrik, yaitu Arus disetiap phasa, Tegangan line to line, Tegangan line to netral, Daya Aktif, Daya Reaktif, Daya Semu dan Faktor daya. Selain itu, pada visualisasi dapat juga dilihat kecenderungan data yang ada terhadap waktu dalam bentuk Grafik dan Tabel.
\end{abstract}

Kata Kunci: Web-Scada, Monitoring

\section{PENDAHULUAN}

Pengukuran penggunaan energi listrik merupakan proses sebuah manajemen energi listrik yang sangat penting sehingga dengan mudah proses penghematan dan efisiensi bisa diperoleh. Oleh karena itu untuk mengetahui besarnya energi listrik yang sedang terpakai, perlu dilakukan pengukuran penggunaan energi listrik tersebut.

Pada umumnya sistem pengukuran energi listrik dilakukan secara manual dan konvensional dengan menggunakan alat ukur yang bersifat portable (tidak permanen) dan memerlukan pengetahuan dan keterampilan dalam menggunakannya, selain itu dalam mengumpulkan data hasil pengukuran membutuhkan waktu yang cukup lama. Karena tidak semua orang dapat menggunakan, maka dibutuhkan suatu sistem pengukuran dimana data hasil pengukuran yang ditampilkan dapat dipahami penggunanya sekalipun bagi pengguna (dalam hal ini operator yang bersangkutan) yang berlatar belakang pengetahuan non listrtik.

Sistem pendukung yang akan dibuat terdiri dari perangkat keras dan perangkat lunak yang saling terintegrasi. Kemudian hasil integrasi tersebut selanjutnya ditampilkan dalam bentuk visualisasi yang mudah dipahami oleh operator sehingga dapat menentukan kebijakan yang tepat dalam konsumsi energi berkaitan dengan penyediaan dan pengelolaan energi yang lebih optimal.

Sistem ini diimplementasikan pada Gedung Teknik Elektro Politeknik Negeri Ujung Pandang, Sistem tersebut akan membaca data besaran listrik berupa tegangan, arus, daya, dan factor daya secara real time yang diolah oleh sistem.

Dengan demikian tugas akhir ini bertujuan untuk memodifikasi peralatan yang sudah terpasang,dimana hasil pengukuran besaran listrik secara real time dapat diakses melalui jaringan web menggantikan sistem pengukuran secara manual dan konvensional agar dapat 
mempermudah operator dalam membuat keputusan-keputusan terkait pada gedung Teknik Elektro Politeknik Negeri Ujung Pandang

\section{LANDASAN TEORI}

Implementasi adalah suatu tindakan atau pelaksanaan dari sebuah rencana yang sudah disusun secara matang dan terperinci. Implementasi biasanya dilakukan setelah perencanaan sudah dianggap sempurna. Implementasi adalah bermuara pada aktivitas, aksi, tindakan atau adanya mekanisme suatu sistem, implementasi bukan sekedar aktivitas, tapi suatu kegiatan yang terencana dan untuk mencapai tujuan kegiatan (Usman, 2002). Dari pengertian diatas dapat disimpulkan implementasi adalah suatu kegiatan yang terencana, bukan hanya suatu aktifitas dan dilakukan secara sungguh-sungguh berdasarkan acuan norma- norma tertentu untuk mencapai tujuan kegiatan. Oleh karena itu, impelementasi tidak berdiri sendiri tetapi dipengaruhi oleh objek berikutnya yaitu kurikulum. Implementasi kurikulum merupakan proses pelaksanaan ide, program atau aktivitas baru dengan harapan orang lain dapat menerima dan melakukan perubahan terhadap suatu pembelajaran dan memperoleh hasil yang diharapkan.

SCADA merupakan singkatan dari Supervisory Control and Data Acquisition, SCADA merupakan sebuah sistem yang mengawasi mengontrol dan mengumpulkan informasi atau data-data dari lapangan dan kemudian mengirimkannya ke sebuah komputer pusat (Master Control) yang akan mengatur dan mengontrol data-data tersebut. Sehubungan dengan itu, (Pandjaitan, 1999) menyatakan bahwa "Sistern SCADA bertujuan untuk membantu perusahaan listrik mendapatkan sistem pengoperasian optimum sesuai dengan berbagai kenyataan kekurangan-kekurangan maupun segala kelebihan yang terdapat pada system tenaga listrik tersebut". Sistem SCADA digunakan diberbagai bidang, Seperti industri Pembangkit, dan pendistribusian tenaga listrik.

Web adalah suatu metode untuk menampilan informasi di internet, baik berupa teks, gambar, suara maupun video yang interaktif dan mempunyai kelebihan untuk menghubungkan (link) satu dokumen dengan dokumen lainnya (hypertext) yang dapat diakses melalui sebuah browser (Yuhefizer).
Membaca Parameter Besaran Listrik melalui So Machine. Melalui aplikasi So Machine ini, parameter-parameter kelistrikan yang akan diukur, dimasukkan sesuai dengan register list power meter yang telah ditentukan agar PLC Schneider dapat membaca besaran listrik yang terdapat pada power meter. Pada program ladder diagram yang akan dibuat, selain untuk mengontrol mekanisme kerja komponen yang digunakan, di ladder diagram ini juga mampu membaca besaranbesaran listrik yang terbaca pada power meter.

Untuk membuat visualisasi scada yang akan digunakan untuk monitoring besaran listrik, digunakan aplikasi Inkscape. Hasil rancangan visualisasi yang telah dibuat inilah, selanjutnya ditampilkan hasil pembacaan data power meter melalui web. Software ini akan menampilkan semua data yang terdapat pada power meter yang meliputi tegangan, arus, daya aktif, daya reaktif, daya semu, dan factor daya. Agar komunikasi antara computer server dengan power meter dapat saling mengerti, maka dibutuhkan sebuah perangkat lunak untuk membantu komunikasi kedua perangkat keras tersebut yaitu IntegraXor buatan Ecava. Melalui IntegraXor ini, parameterparameter kelistrikan yang akan diukur diatur sesuai dengan address yang tertera dalam user manual power meter PM-5350 buatan Schneider.

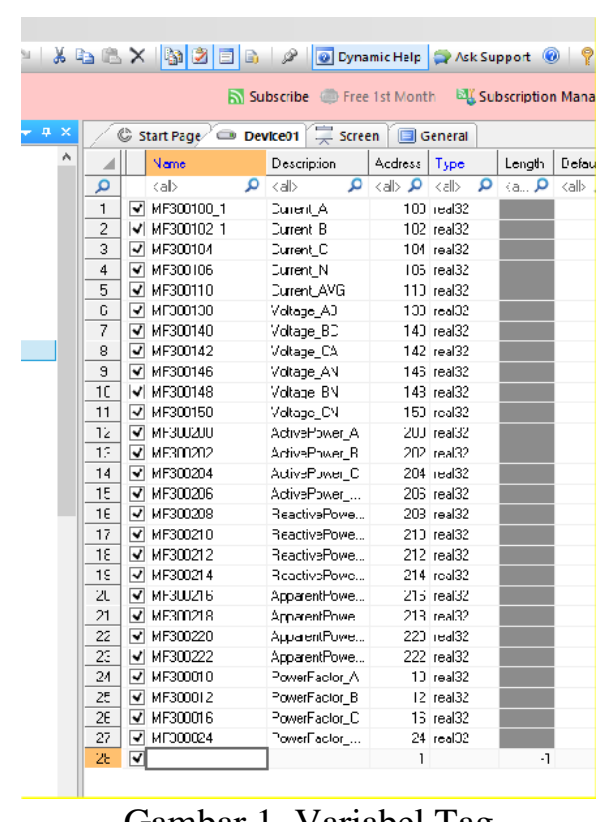

Gambar 1. Variabel Tag

\section{METODE PENELITIAN}

Penelitian ini diawali dengan melakukan studi literatur untuk memahami dasar-dasar teori yang 
berhubungan dengan sistem besaran listrik, sehingga diharapkan mampu memberikan gambaran dalam pembuatan desain web-scada. Kemudian Membuat konsep desain awal, Segala pemikiran ataupun ide-ide yang ada dituangkan dalam suatu desain awal menggunakan software Integraxor, So Machine, dan Inkscape. Setelah semuanya terkonsep, maka langkah selanjutnya adalah pembuatan scada, ladder diagram, dan web menggunakan aplikasi IntegraXor, So Machine, dan Inkscape. Lalu melakukan pengujian sistem, Usaha ini dilakukan untuk mengetahui kemampuan sistem yang telah dibuat, apakah sudah memenuhi keinginan atau belum. Pengujian dilakukan beberapa kali untuk mendapatkan hasil yang diinginkan.

Penelitian ini dilaksanakan pada Politeknik Negeri Ujung Pandang dimana tempat ini merupakan sumber data bagi penulis. Penelitian dan pengambilan data dilakukan selama 2 bulan, pada bulan Mei sampai dengan bulan Juni 2019.

Adapun peralatan serta bahan yang digunakan dalam memodifikasi alat, seperti pada tabel dibawah ini :

\begin{tabular}{lccc}
\multicolumn{4}{c}{ Tabel 1. Peralatan } \\
\hline \multicolumn{4}{c}{ PERALATAN } \\
\hline NAMA & JUMLAH & SATUAN & $\begin{array}{c}\text { SPESIFIKAS } \\
\text { I }\end{array}$ \\
\hline $\begin{array}{l}\text { Phase } \\
\text { Detector }\end{array}$ & 1 & Buah & Kyoritsu \\
\hline $\begin{array}{l}\text { Tang } \\
\text { Ampere }\end{array}$ & 1 & BeW 8035 & Ideal 61-766 \\
\hline
\end{tabular}

Tabel 2. Bahan

BAHAN

\begin{tabular}{|c|c|c|c|}
\hline NAMA & JUMLAH & SATUAN & $\begin{array}{c}\text { SPESIFIKA } \\
\text { SI } \\
\end{array}$ \\
\hline $\begin{array}{l}\text { Panel } \\
\text { distribusi }\end{array}$ & 1 & Buah & $\begin{array}{c}\text { TAV } \\
80 \mathrm{~cm} \mathrm{x} 25 \\
\mathrm{~cm} \times 120 \mathrm{~cm} \\
\end{array}$ \\
\hline $\begin{array}{l}\text { MCB } 3 \\
\text { phasa }\end{array}$ & 1 & & $\begin{array}{c}\text { Schneider } 16 \\
\text { A-230 V }\end{array}$ \\
\hline $\begin{array}{l}\text { MCB 1 } \\
\text { phasa }\end{array}$ & 1 & Buah & $\begin{array}{c}\text { Broco } 4 \text { A- } \\
230 \mathrm{~V}\end{array}$ \\
\hline $\begin{array}{l}\text { Power } \\
\text { Logic } \\
\text { Schneider } \\
\end{array}$ & 1 & Buah & PM-5350 \\
\hline $\begin{array}{l}\text { PLC } \\
\text { Scheineder }\end{array}$ & 1 & Buah & $\begin{array}{c}\text { TM221CE24 } \\
\text { R }\end{array}$ \\
\hline $\begin{array}{l}\text { Schneider } \\
\text { HMI }\end{array}$ & 1 & Buah & $\begin{array}{c}\text { Magelis Easy } \\
\text { GXU3512 }\end{array}$ \\
\hline Kabel & 10 & Meter & $\begin{array}{c}\text { Eterna NYAF } \\
2.5 \mathrm{~mm}\end{array}$ \\
\hline
\end{tabular}

Dalam modifikasi alat monitoring besaran listrik melalui jaringan web terhadap power meter ini dibagi atas dua tahap yaitu modifikasi sistem kelistrikan dan perencanaan software. Yang dimaksud dengan modifikasi sistem kelistrikan adalah instalasi kabel pada komponen-komponen di dalam panel hubung bagi yang akan digunakan dalam pengukuran besaran-besaran listrik.

System monitoring pada skripsi ini adalah mengambil, menyiapkan, dan menampilkan data besaran listrik yang dikonsumsi oleh peralatan listrik di gedung Teknik Elektro Politeknik Negeri Ujung Pandang. Data konsumsi besaran listrik disimpan dalam sebuah komputer server yang dapat diakses melalui client yang terhubung dengan jaringan yang dipancarkan oleh computer server dalam jaringan web.

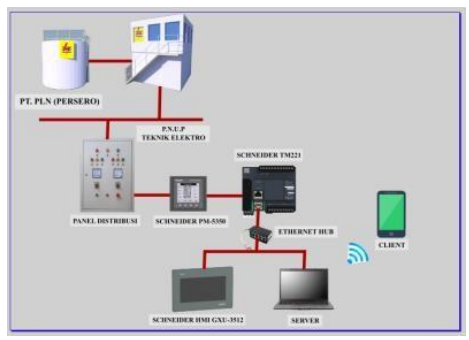

Gambar 2. Skema Sistem Monitoring Besaran Listrik

Melalui aplikasi So Machine ini, parameter-parameter kelistrikan yang akan diukur, dimasukkan sesuai dengan register list power meter yang telah ditentukan agar PLC Schneider dapat membaca besaran listrik yang terdapat pada power meter. Pada program ladder diagram yang akan dibuat, selain untuk mengontrol mekanisme kerja komponen yang digunakan, di ladder diagram ini juga mampu membaca besaranbesaran listrik yang terbaca pada power meter.

Agar komunikasi antara computer server dengan power meter dapat saling mengerti, maka dibutuhkan sebuah perangkat lunak untuk membantu komunikasi kedua perangkat keras tersebut yaitu IntegraXor buatan Ecava.

Melalui IntegraXor ini, parameter-parameter kelistrikan yang akan diukur diatur sesuai dengan address yang tertera dalam user manual power meter PM-5350 buatan Schneider. Untuk merancang visualisasi pada computer server digunakan perangkat lunak Inkscape V.0.91, software ini akan menampilkan semua data yang terdapat pada power meter, yaitu tgangan, arus, daya aktif, daya reaktif, daya semu, dan factor daya.

\section{HASIL DAN PEMBAHASAN}

Pada bagian ini, penulis akan menampilkan hasil pengukuran besaran listrik yang mana 
PC server telah dihubungkan dengan power meter PM-5350 menggunakan kabel Ethernet. gambar berikut akan menunjukkan pengukuran besaran listrik pada software IntegraXor.

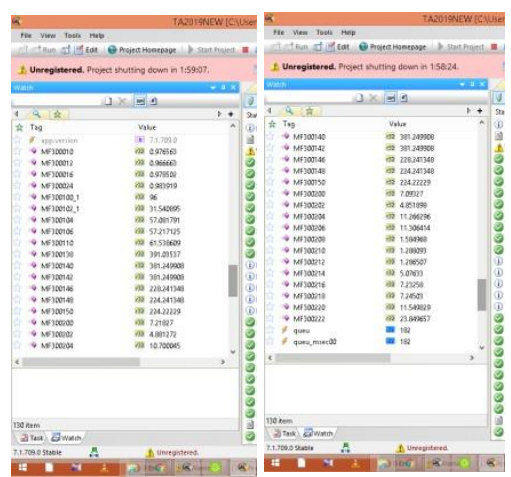

Gambar 3. Pengukuran besaran listrik pada software IntegraXor

Hasil pengukuran tersebut akan ditampilkan oleh PC server memanfaatkan scada software IntegraXor. Gambar-gambar berikut merupakan hasil monitoring data besaran listrik melalui jaringan web dengan menggunakan bantuan perangkat lunak IntegraXor.

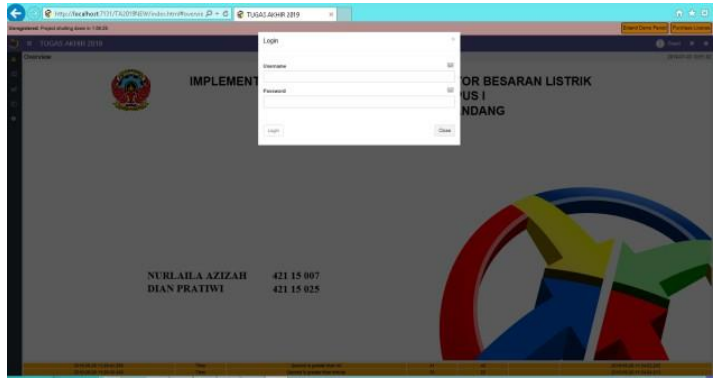

Gambar 4. Halaman Login

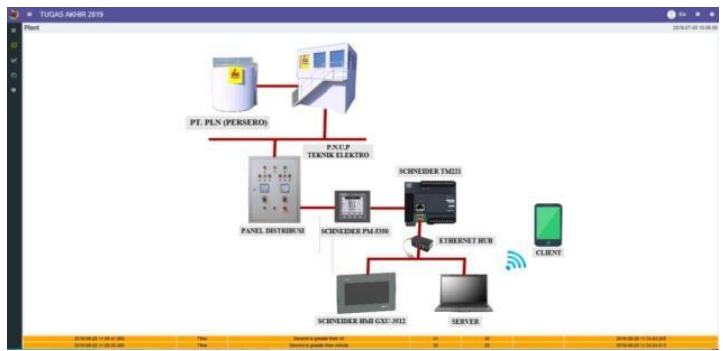

Gambar 5. Blok diagram sistem pada halaman Overview pada komputer client

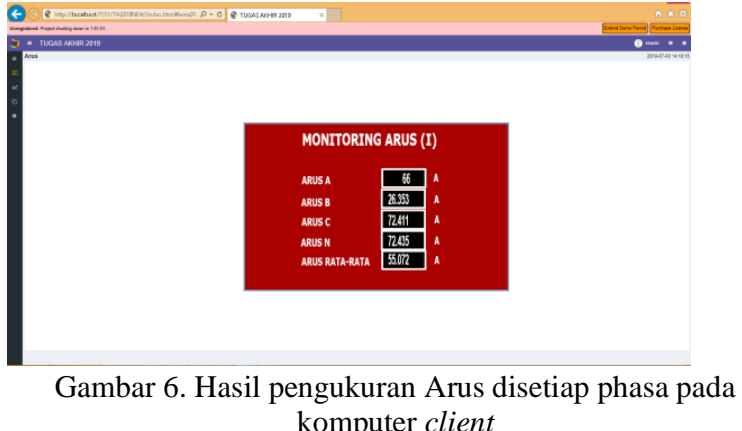
komputer client

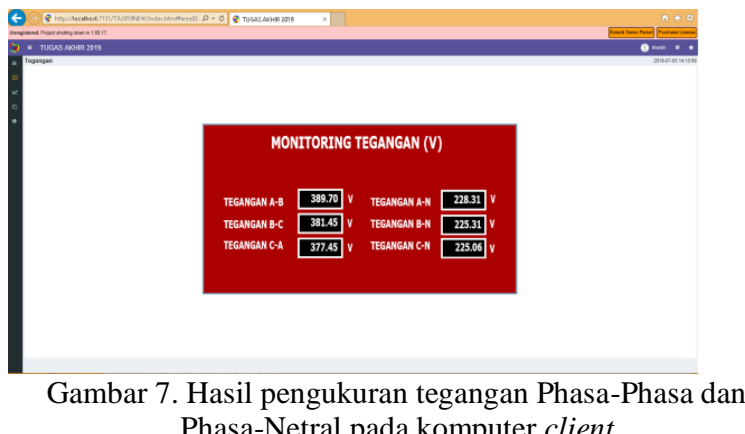
Phasa-Netral pada komputer client
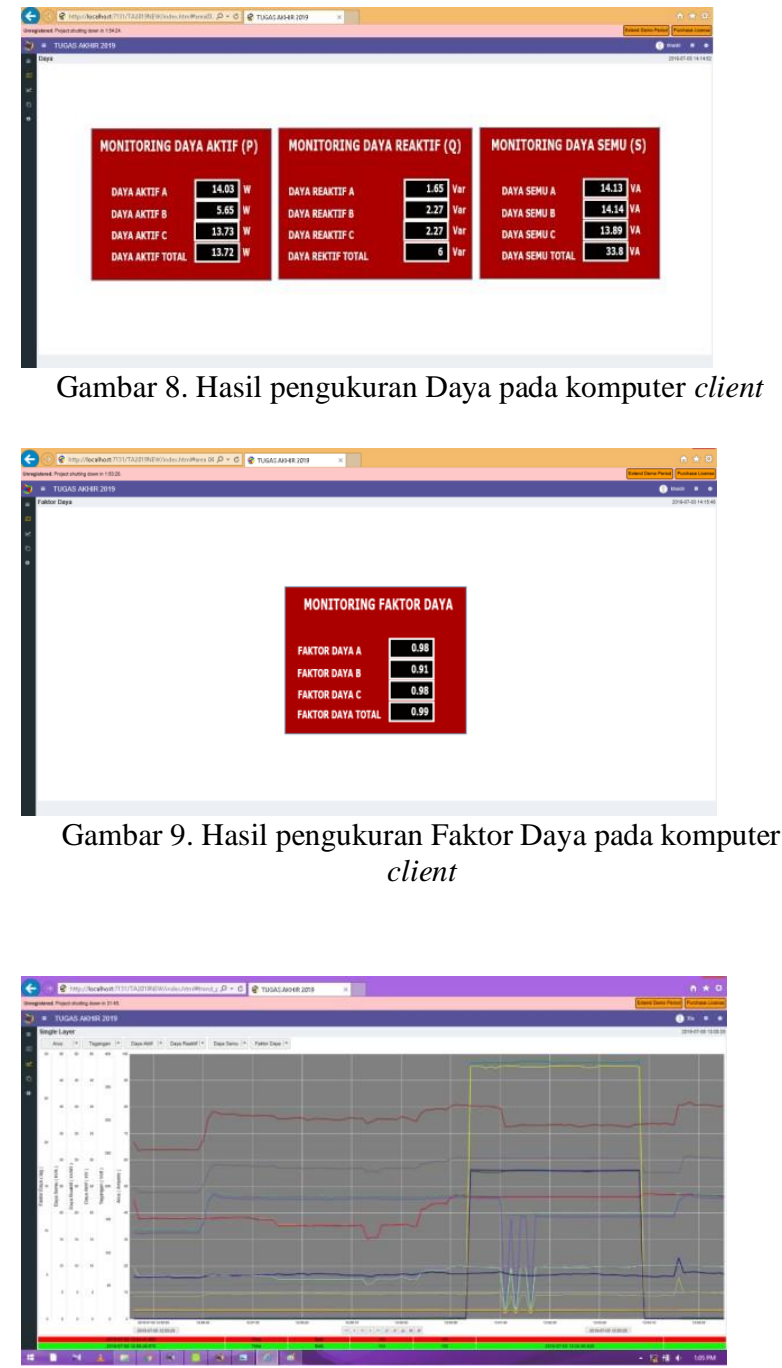

Gambar 10. Hasil Grafik besaran listrik pada computer client 


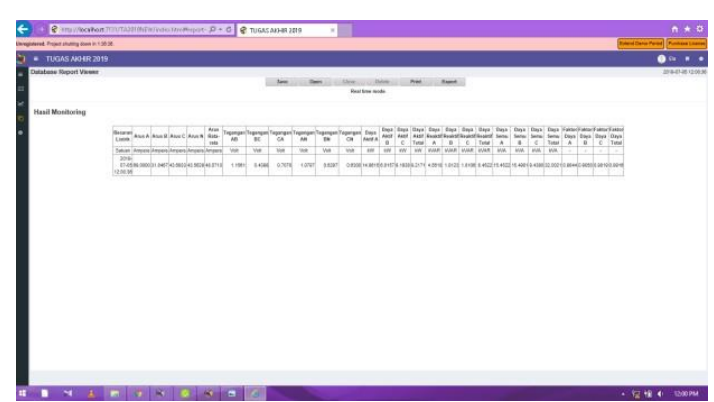

Gambar 11. Tampilan laporan atau hasil data pengukuran yang tersimpan secara real time pada halaman Report pada komputer client

Data besaran listrik yang diukur oleh power meter akan secara otomatis terbaca pada software So Machine, aplikasi ini merupakan software penerjemah bahasa dua peralatan yang berbeda yaitu power meter disisi RTU (Remote Terminal Unit) dan computer pada sisi MTU (Master Terminal Unit) agar kedua peralatan ini dapat berkomunikasi. Kemudian setelah data pengukuran terbaca pada software So Machine ini, maka selanjutnya membuat variable tag diaplikasi IntegraXor, agar data hasil pengukuran power meter yang dibaca oleh So Machine dapat dijelajahi oleh software IntegraXor, kemudian disajikan hasil pengukuran tersebut dalam bentuk visual atau biasa disebut dengan scada. Untuk mengakses hasil monitoring besaran listrik dalam bentuk visualisasi scada, syarat utama yang harus dipenuhi adalah perangkat harus terhubung dengan koneksi internet, dan juga mengaksesnya melalui browser web standar. Dari hasil monitoring besaran listrik melalui web-scada, menunjukkan :

Tabel 3. Perbandingan Hasil Monitoring

\begin{tabular}{lccc}
\hline $\begin{array}{c}\text { Nama } \\
\text { Parameter }\end{array}$ & Web & $\begin{array}{c}\text { Power } \\
\text { meter }\end{array}$ & \% Error \\
\hline Arus A & 84 & 82.93 & 1.290245 \\
\hline Arus B & 23.72 & 23.8 & 0.337268 \\
\hline Arus C & 53.45 & 52.85 & 1.135289 \\
\hline Arus N & 53.3 & 50.99 & 4.5303 \\
\hline Arus Rata-rata & 53.778 & 53.2 & 1.086466 \\
\hline Tegangan A-B & 392.3 & 392.23 & 0.017847 \\
\hline Tegangan B-C & 384.59 & 384.32 & 0.070254 \\
\hline Tegangan C-A & 380.59 & 381.47 & 0.230687 \\
\hline Tegangan A-N & 227.08 & 227.14 & 0.026415 \\
\hline Tegangan B-N & 227.08 & 227.01 & 0.030836 \\
\hline Tegangan C-N & 227.3 & 214.17 & 6.130644 \\
\hline Daya Aktif A & 18.2 & 18.11 & 0.496963 \\
\hline Daya Aktif B & 5.25 & 5.25 & 0 \\
\hline Daya Aktif C & 11.13 & 11.21 & 0.713649 \\
\hline Daya Aktif & 11.16 & 34.59 & 67.73634 \\
\hline Total & 3.69 & 3.61 & 2.216066 \\
\hline Daya Reaktif A & 1.26 & 1.28 & 1.5625 \\
\hline Daya Reaktif B & & &
\end{tabular}

\begin{tabular}{lccc}
\hline $\begin{array}{c}\text { Nama } \\
\text { Parameter }\end{array}$ & Web & $\begin{array}{c}\text { Power } \\
\text { meter }\end{array}$ & \% Error \\
\hline Daya Reaktif C & 1.26 & 1.91 & 34.03141 \\
\hline $\begin{array}{l}\text { Daya Reaktif } \\
\text { Total }\end{array}$ & 6.97 & 6.81 & 2.349486 \\
\hline Daya Semu A & 18.5 & 18.49 & 0.054083 \\
\hline Daya Semu B & 18.51 & 5.41 & 242.1442 \\
\hline Daya Semu C & 11.32 & 10.56 & 7.19697 \\
\hline $\begin{array}{l}\text { Daya Semu } \\
\text { Total }\end{array}$ & 35.29 & 34.46 & 2.40859 \\
\hline Faktor Daya A & 0.98 & 0.98 & 0 \\
\hline Faktor Daya B & 0.97 & 0.97 & 0 \\
\hline Faktor Daya C & 0.98 & 0.98 & 0 \\
\hline $\begin{array}{l}\text { Faktor Daya } \\
\text { Total }\end{array}$ & 0.98 & 0.98 & 0 \\
\hline
\end{tabular}

Pada tabel diatas, merupakan perbandingan hasil monitoring pada web dan pada power meter langsung. Beberapa parameter besaran listrik menunjukkan kualitas hasil monitoring yang baik dengan selisih error atau perbandingan nilai yang hanya berbeda tipis. Namun ada juga parameter besaran listrik yang menunjukkan selisih error yang besar atau tidak wajar hingga $242 \%$. Hal itu dapat terjadi karena penentuan pengalamatan pada alamat memory dan penentuan besar quantity dan quality yang bisa saja keliru.

\section{KESIMPULAN}

Berdasarkan hasil penelitian dan hasil percobaan yang diperoleh dengan menggunakan bantuan perangkat lunak So Machine, IntegraXor, Inkscape, dan Microsoft Access, maka diperoleh kesimpulan :

Monitoring besaran listrik pada gedung Teknik Elektro Politeknik Negeri Ujung Pandang menggunakan software So Machine dengan IntegraXor. So Machine merupakan software yang berfungsi mengumpulkan data-data hasil pengukuran besaran listrik pada power meter dan selanjutnya software IntegraXor mengakses data-data hasil pengukuran besaran listrik yang telah dikumpulkan oleh So Machine dan menyajikan dalam bentuk visual. Komunikasi antara power meter dengan sebuah PLC, menggunakan kabel Ethernet dengan bantuan software So Machine, yaitu dengan memasukkan register address parameter-parameter yang akan diukur agar selanjutnya computer server yang terhubung dengan aplikasi IntegraXor dapat mengakses hasil pengukuran tersebut dan disajikan 
dalam bentuk visual yang dapat diakses melalui jaringan web.

Monitoring besaran listrik melalui jaringan web pada gedung Teknik Elektro Politeknik Negeri Ujung Pandang, menghubungkan computer client dengan computer server melalui jaringan yang dipancarkan oleh computer server dan terhubung dengan koneksi internet sehingga computer client mendapat akses untuk melihat hasil monitoring pada computer server melalui web.

\section{UCAPAN TERIMA KASIH}

Sebagai manusia biasa, penulis sangat menyadari bahwa tugas akhir ini, banyak sekali pihak yang terlibat dan berperan serta untuk mewujudkan selesainya tugas akhir ini, karena itu pada tempatnya lah ingin menyampaikan rasa hormat dan ucapan terima kasih yang setinggitingginya kepada mereka yang secara moril maupun materil telah banyak membantu penulis untuk merampungkan tugas akhir ini hingga selesai.

Pertama-tama ucapan terima kasih penulis haturkan secara khusus kepada orang tua yang penulis hormati dan cintai ayahanda dan ibunda yang telah membesarkan penulis dan selalu memberikan dorongan agar cepat menyelesaikan studi penulis dengan penuh kesabaran dan juga pada saudara-saudara penulis yang dengan semangat dan dorongannya selama ini.

Penulis haturkan terima kasih kepada Bapak Ir. Muhammad Anshar, M.Si., Ph.D selaku direktur Politeknik Negeri Ujung Pandang, Ibu Ir. Hafsah Nirwana, M.T selaku ketua Jurusan Teknik Elektro dan Bapak Sofyan S.T., M.T selaku ketua Program Studi D-4 Teknik Listrik yang selama ini telah membantu penulis hingga dapat menyelesaikan studi di Politeknik Negeri Ujung Pandang.

Selanjutnya ucapan terima kasih penulis haturkan kepada kedua pembimbing penulis Bapak Hamdani S.T.,M.T selaku Pembimbing I dan Bapak Ir. Syarifuddin, M.T selaku Pembimbing II yang mana keduanya dengan penuh kesabaran memberikan bimbingannya dalam penyelesaian tugas Akhir ini.

Juga kepada para dosen dan teknisi Program Studi Listrik serta rekan-rekan mahasiswa khususnya kelas A Teknik Listrik D-4 angkatan 2015 yang banyak memberikan dorongan moril sehingga tugas Akhir ini selesai pada waktunya. Pada kesempatan ini, harapan penulis, semoga bantuan selama ini secara moril maupun materiil mendapatkan imbalan amal dari Allah SWT dan semoga laporan tugas akhir ini dapat memberikan manfaat bagi semua. Wassalamu Alaikum Wr. Wb.

\section{REFERENSI}

[1] Capiel. (1982). Sistem SCADA.

[2] http://toekangplc.com/2013/01/30/s7-1200integraxor-web-hmi/). (n.d.). Retrieved November 10, 2018

[3] https://dosenkomputer.com/pengertian-ethernet- danfungsinya-serta-jenisnya/. (n.d.).

Retrieved Juni 26, 2019

[4] https://id.wikipedia.org/wiki/Microsoft_Access. (n.d.). Retrieved Juni 28, 2019

[5] Inkscape. (n.d.). Retrieved Juni 28, 2019, from https://inkscape.id.downloadast

[6] IntegraXor. (n.d.). Retrieved Juni 25, 2019, from IntegraXor: www.integraxor.com/doc/ug.pdf

[7] Integraxor WEB . (n.d.). Retrieved November 10, 2018, from http://toekangplc.com/2013/01/30/s7-1200integraxor-web-hmi/)

[8] Pandjaitan. (1999). Retrieved from http://repo.unand.ac.id/id/file/2790.

[9] Pengertian Java. (n.d.). Retrieved Juni 25, 2019, from Nesabmedia : https://www.nesabamedia.com/pengertianjava/

[10] Sejarah JAVA. (n.d.). Retrieved Juni 25, 2019, from Kominfo: https://bpptik.kominfo.go.id/2012/06/04/257/s ejarah-java/

[11] Usman, N. (2002). Retrieved Oktober 2018, from https://www.zonareferensi.com/pengertian-

implementasi/.

[12] Whitten, Bentle, \& Barlow. (1993). Retrieved Oktober 2018, from https://www.zonareferensi.com/pengertian- implementasi/. [13] Yuhefizer. (n.d.). Retrieved November 2018, from https://sahabatartikel.co.id/2018/03/7- pengertian-websitemenurut-para-ahli- terlengkap/. 